\title{
CONCEPÇÕES DE PROFESSORAS ACERCA DO DESENVOLVIMENTO DA LINGUAGEM DE CRIANÇAS PARTICIPANTES DE UM PROGRAMA DE ESTIMULAÇÃO ESSENCIAL
}

\author{
Karolina Siebert Sapelli SCHADECK ${ }^{1}$ \\ Jáima Pinheiro de OLIVEIRA ${ }^{2}$
}

RESUMO: O presente estudo teve por objetivo identificar as concepções de professoras acerca do desenvolvimento da linguagem de crianças participantes de um programa de estimulação essencial. Participaram do estudo duas professoras e duas auxiliares que atuam numa Escola de Ensino Básico, na modalidade de Educação Especial (APAE), de um município do interior do Paraná. Foram realizadas entrevistas semiabertas, com o uso de um roteiro semiestruturado. $\mathrm{O}$ registro das entrevistas foi realizado com gravador. Em seguida, estas foram transcritas na íntegra e analisadas por meio de categorização temática. A partir dos dados coletados, foram elaboradas cinco categorias de análise. Foi utilizado como base dessa discussão, o referencial teórico de Vygotsky, além de estudos atuais sobre a temática. As entrevistas evidenciaram que as concepções das participantes sobre linguagem estão intimamente relacionadas ao desenvolvimento da fala, relativizando a importância das outras formas de linguagem e até mesmo estabelecendo confusões entre oralidade e linguagem. Além disso, prevalece nos relatos das participantes a função comunicativa da linguagem, e são praticamente inexistentes concepções sobre a importância desta habilidade para as demais funções psicológicas superiores ou como conteúdo estruturante da escolarização destas crianças.

PALAVRAS-CHAVE: Educação especial. Estimulação essencial. Linguagem.

\section{Sobre a estimulação essencial e a linguagem}

É possível encontrar na literatura da área diversos conceitos e definições sobre a estimulação essencial. No Brasil, o Ministério da Educação (BRASIL, 1995) conceitua estimulação essencial ${ }^{3}$ como sendo um “[...] conjunto dinâmico de atividades e de recursos humanos e ambientais incentivadores que são destinados a proporcionar à criança, nos seus primeiros anos de vida, experiências significativas para alcançar pleno desenvolvimento no seu processo evolutivo.” (BRASIL, 1995, p.11). Ou seja, um dos

\footnotetext{
${ }^{1}$ Graduada em Psicologia. Especialista em Educação Especial. Mestre em Educação. UNICENTRO Universidade e da Universidade Estadual do Centro-Oeste. Paraná. Guarapuava - PR - Brasil. 85040-080 - karol_sapelli@hotmail.com.

${ }^{2}$ Pós-doutora em Educação. UNESP - Universidade Estadual Paulista Júlio de Mesquita Filho. Mestre em Educação Especial. UFSCar - Universidade Federal de São Carlos. Professora Assistente Doutora do Departamento de Educação Especial. UNESP - Universidade Estadual Paulista Júlio de Mesquita Filho, Faculdade de Filosofia e Ciências. Marília - SP - Brasil. 17525-900 - jaimafono@gmail.com.

${ }^{3}$ É importante ressaltar que no documento em referência, o MEC (BRASIL, 1995) opta por utilizar o termo Estimulação Precoce por ser mais difundido na época, mas esclarece ao longo do texto que é apenas uma diferença de nomenclatura.
} 
principais documentos que embasam os programas de estimulação essencial brasileiros considera que os mesmos devem oferecer às crianças atendidas a oportunidade de conviver com pessoas, objetos e espaços, incentivando uma interação ativa com o ambiente, intencionando o pleno desenvolvimento de suas potencialidades. É preciso lembrar que desde a publicação deste documento já ocorreram inúmeras mudanças na legislação da Educação, no que se refere especialmente às políticas de inclusão de pessoas com necessidades educacionais especiais (BRASIL, 2008). Entretanto, o mesmo continua servindo como referência principal para as intervenções em estimulação essencial.

O Ministério da Educação (BRASIL, 2008) sugere que a equipe para tais intervenções seja constituída pelos seguintes profissionais: professor com formação em Psicologia, Pedagogia, ou Educação Física; Psicólogo; Fonoaudiólogo; Assistente Social; Fisioterapeuta; Terapeuta Ocupacional; Médico (pediatra, otorrinolaringologista, oftalmologista, neurologista, fisiatra) e Técnico em eletrônica (para manutenção de aparelhos de ampliação sonora). No caso de crianças com deficiência no crescimento, devem atuar conjuntamente pediatras, enfermeiros, nutricionistas, fonoaudiólogos, patologistas e psicólogos, além do envolvimento da família, para que os resultados sejam bem-sucedidos (DESSEN; COSTA JUNIOR, 2005; NUNES; AIELLO, 2008).

Neste contexto do desenvolvimento infantil, sem dúvida, a linguagem ocupa lugar de destaque, seja pelo seu caráter comunicativo, seja pela importância dessa habilidade enquanto constituinte do sujeito. Vygotsky afirma que a linguagem é o mais complexo sistema de signos criado pelo ser humano (OLIVEIRA, 1992). Para ele, tratase de um sistema simbólico que permite a comunicação e a formação de conceitos, ou seja, é o veículo pelo qual as pessoas tornam-se capazes de organizar as informações em categorias. Verifica-se então que a linguagem assume para o homem duas funções: a de mediadora da interação humana, ou seja, possibilita a comunicação com o outro, e a função de pensamento generalizante, que permite ao homem conhecer, nomear e interpretar o mundo à sua volta, ou seja, apropriar-se de sua cultura.

Essas funções são suficientes para nos convencer da tamanha importância que tal habilidade adquire nos processos de desenvolvimento e aprendizagem, de modo geral. E, neste sentido, torna-se difícil imaginar como seria a vida de um sujeito que não consegue se apropriar deste signo, de maneira satisfatória. No entanto, isso pode acontecer: seja por questões biológicas ou por questões sociolinguísticas, a exemplo de interações sociais (iniciais) insuficientes ou de uma baixa qualidade. Muitos destes 
casos estão relacionados com as crianças com necessidades educacionais especiais. E, um dos objetivos dos programas de estimulação essencial é suprir essas necessidades, para que os processos de desenvolvimento infantil, aprendizagem e de formação humana, de modo geral, ocorram de maneira mais satisfatória possível.

Nesse contexto, a literatura atual tem indicado cada vez mais que o paradigma de suporte (ARANHA, 2001, grifo nosso) em educação especial é o que mais pode atender a esta demanda, em razão da perspectiva social sobre a pessoa com deficiência, prevista nas obras de Vygotsky e de outros autores Contextualistas. Faz-se necessária a superação crescente da ideia de que a pessoa com deficiência deve se adaptar às condições oferecidas pelo meio, como se o sucesso ou fracasso de tais pessoas fosse um mérito essencialmente individual. Deve-se sim, investir em um processo mediador que possibilite o desenvolvimento das potencialidades e capacidades de compensação da pessoa com deficiência, mas é preciso também despertar não apenas nas instituições escolares, mas na sociedade em geral a consciência de que o processo de inclusão depende muito mais das condições de suporte que são oferecidas às pessoas com deficiência, do que de suas habilidades biológicas e individuais.

\section{Sobre as concepções de profissionais acerca do desenvolvimento da linguagem e do processo de ensino de crianças com necessidades especiais}

Muitos estudos priorizam as análises de concepções de professores e da população, em geral, acerca de aspectos da saúde (WARREN et al., 2004), do desenvolvimento infantil (HEKAVEI; OLIVEIRA, 2009), de aspectos mais específicos, como o processo de inclusão escolar (CAPELLINI; RODRIGUES, 2009), dentre outros. Essas percepções devem ser consideradas pelos profissionais, em todas as suas dimensões, para que seja aperfeiçoar as relações profissionais e os processos de desenvolvimento e ensino-aprendizagem.

Pereira-Silva e Dessen (2007) investigaram os valores e as crenças de pais e professores sobre as práticas de cuidados e socialização de crianças com e sem Síndrome de Down. As autoras consideraram o desenvolvimento motor, a escolarização, a profissionalização, as relações íntimas e as expectativas quanto ao futuro. Os resultados indicaram diferenças nos valores e crenças relatados pelos pais de crianças com e sem síndrome de Down, especialmente no que se refere ao desenvolvimento motor. As professoras do ensino regular relataram expectativas 
imediatas referentes às mudanças no desempenho acadêmico das crianças com desenvolvimento típico, bem como em seus relacionamentos sociais. Por outro lado, as professoras do ensino especial esperam progressos nos resultados acadêmicos, em longo prazo. Os dados indicaram semelhanças entre as crenças de pais e professoras, com foco para a crença de que o apoio e o envolvimento da família podem propiciar à criança com síndrome de Down os avanços necessários ao seu desenvolvimento.

Cardoso et al. (2003) realizaram um estudo com o objetivo de verificar o conhecimento de mães e auxiliares do desenvolvimento infantil sobre o processo de desenvolvimento da linguagem em crianças de 0 a 24 meses de idade. As autoras fizeram aplicação de questionário e dentre os principais resultados destacaram as relações significativas referentes ao nível de escolaridade e o nível de conhecimento acerca do processo de desenvolvimento de linguagem das crianças nessa faixa etária. As mães que indicaram maior conhecimento sobre o assunto tinham maior nível de escolaridade. No entanto, há outros estudos que não indicam relação direta entre o nível de escolaridade, nível socioeconômico e as habilidades de cuidado do desenvolvimento infantil (MAJNEMER; ROSENBLATT, 1994).

De Nardin e Menezes (2008) também realizaram uma pesquisa com o intuito de compreender as concepções de docentes em relação ao aluno com necessidades educacionais especiais. Para isto, foram realizadas entrevistas com sete professores atuantes no Ensino Fundamental e no Ensino Médio, que trabalham com estes alunos. As autoras apresentam como resultados a falta de formação, de acordo com o relato dos participantes, para trabalhar com alunos com necessidades educacionais especiais. Os participantes também apontaram a importância da inclusão para a convivência social de tais alunos com os demais. Além disso, percebeu-se que os professores atribuem a deficiência a questões orgânicas e individuais, e não a uma construção social. Diante disto, as autoras apontam para a necessidade de implementação de políticas pedagógicas e curriculares que levantem questionamentos acerca da construção das diferenças em nossa sociedade.

Quatrin e Pivetta (2008) investigaram as concepções de docentes sobre a inclusão escolar, por meio da aplicação de um questionário a onze professores da rede estadual de Santa Maria - RS. Tais professores atuavam em classes especiais, e também com alunos incluídos em classes comuns. A maior parte dos participantes apresentou uma visão positiva sobre a inclusão, sendo que vários a consideram como uma oportunidade de estimular o desenvolvimento do aluno com necessidades educacionais 
especiais. Entretanto, ao mesmo tempo os participantes relatam sentimentos de impotência e despreparo diante da atuação diária junto a tais alunos. Para as autoras, estes resultados revelam não apenas a contradição entre o discurso e a prática diárias dos professores, mas também a fragilidade das políticas públicas relacionada à inclusão, especialmente aquelas relacionadas à formação destes profissionais.

Especificamente com relação à estimulação essencial, Brust e Lopes (2010) realizaram uma pesquisa para analisar as concepções e conhecimentos de oito professores acerca do tema ${ }^{4}$. Os participantes atuavam na rede municipal do interior do Rio Grande do Sul, em turmas de educação infantil, e participaram de entrevistas semiestruturadas com as pesquisadoras. As autoras afirmam que nenhum dos participantes soube definir com precisão o que é estimulação essencial, e a maioria não conseguiu apontar os benefícios da mesma para o desenvolvimento infantil. Além disso, a maioria compreende que a estimulação é uma modalidade educacional restrita a crianças com deficiência. Diante disto, as autoras apontam para a importância de que os conhecimentos sobre a estimulação essencial sejam mais difundidos entre professores de educação infantil.

Diante desse breve panorama, sabemos que ainda são necessários muitos esforços que contribuam com as intervenções voltadas para o aperfeiçoamento dos programas de educação especial, incluindo os de estimulação essencial, e um dos pontos fundamentais, sem dúvida, deve ser a continuidade de estudos que abordem a construção de novos conhecimentos sobre essa realidade. Conhecer e valorizar as percepções trazidas pelos cuidadores e particularmente pelas mães implica em ampliar a compreensão por parte desta população dos valores que a mesma possui e que podem ser utilizados no sentido de auxiliar em todo o processo de desenvolvimento infantil. Levando isso em consideração, este estudo teve como objetivo identificar concepções de professoras acerca do desenvolvimento da linguagem de crianças participantes de um programa de estimulação essencial. De maneira secundária, buscamos identificar nos relatos destas profissionais, articulações entre esta habilidade e a etapa de ensino na qual estas crianças se encontram.

\section{Método}

${ }^{4} \mathrm{O}$ termo utilizado pelas autoras é Estimulação Precoce. 
Participaram desta pesquisa todas as professoras e auxiliares das turmas de estimulação essencial de uma APAE de um município de médio porte do interior do Estado do Paraná. Não foi preciso estabelecer critérios de inclusão e exclusão, pelo número reduzido (4) de participantes e pelo fato de nenhuma delas apresentar recusa em participar da pesquisa. Indica-se a seguir o perfil das participantes:

- P1 - Professora; 50 anos de idade; Formação em Magistério com adicionais em deficiência mental; Graduação em História; Especialização em Deficiência Mental; 16 anos de experiência em educação especial, e 11 anos em estimulação essencial.

- $\quad$ P2 - Professora; 48 anos de idade; Formação em Magistério com adicionais em deficiências mental, visual, física e auditiva; Graduação em Letras/Espanhol; Especialização em Educação Especial; 31 anos de experiência em educação especial, e 11 anos em estimulação essencial.

- $\quad$ P3 - Auxiliar; 37 anos de idade; Ensino Médio completo; 1 ano de 2 meses de experiência em educação especial, e o mesmo tempo em estimulação essencial.

- P4 - Auxiliar; 27 anos de idade; Ensino Médio completo; 1 anos de experiência em educação especial, e o mesmo tempo em estimulação essencial.

Percebe-se, que apenas as professores (P1 e P2) possuem formação específica em Educação Especial, e tempo significativo de experiência na área. A idade média das participantes é de 40,5 anos de idade. O tempo médio de experiências das professoras em educação especial é de 23,5 anos, e em estimulação essencial é de 11 anos. O tempo médio de experiência das auxiliares é de 1 ano e 1 mês, tanto em Educação Especial quanto na estimulação essencial.

Como instrumento de coleta foi utilizado um roteiro semiestruturado para a realização de uma entrevista semiaberta. Este roteiro foi composto por oito questões base, que serviram como ponto de partida para outros questionamentos que fossem necessários, ao longo da entrevista. As questões base procuravam identificar as concepções das participantes sobre a importância da estimulação essencial para o desenvolvimento das crianças atendidas, e mais especificamente o desenvolvimento da linguagem. Além disso, investigaram práticas das participantes que contribuem para estes aspectos. Como materiais foram utilizados: a) um gravador digital para gravação em áudio das entrevistas. b) um computador para armazenamento dos arquivos de áudio e das transcrições das entrevistas. 
As entrevistas foram transcritas na íntegra e os dados foram revisados exaustivamente, até que fosse possível o estabelecimento de categorias de análise. Foram elencadas cinco categorias com temas que apareceram de forma recorrente nas falas das participantes, e que possuem relação com os objetivos da pesquisa. São elas: 4.1 Aspectos gerais do programa de estimulação essencial; $4.2 \mathrm{O}$ planejamento das atividades na estimulação essencial e a implicação deste planejamento no processo de desenvolvimento linguístico; $4.3 \mathrm{O}$ lugar da linguagem no programa de estimulação essencial; 4.4 A importância da ludicidade articulada à estimulação essencial e ao desenvolvimento da linguagem e; 4.5 Dificuldades encontradas pelas professoras na estimulação essencial relacionadas aos aspectos de linguagem.

\section{Resultados e discussão}

\section{Aspectos gerais do programa de estimulação essencial}

Todas as entrevistadas consideram que o trabalho realizado pela estimulação essencial apresenta impacto positivo sobre o desenvolvimento das crianças atendidas, ou seja, pensam que a estimulação essencial é uma etapa importante da educação das crianças com necessidades educacionais especiais. É possível observar algumas falas que exemplificam isto a seguir:

"[...] ela (a estimulação essencial) auxilia bastante para a socialização da criança, porque muitas vezes a gente vê que elas chegam aqui e são bastante isolados, brincam sozinhos, ou não brincam. No grupinho, a gente trabalhando junto, elas vão desenvolvendo a socialização. [...] Na estimulação essencial a gente vê bastante mudança neles. Por isso é bom trabalhar com eles, é bem visivel". (P1)

"Falando no todo: na parte da fala, na parte motora, na parte visual [...] Eu acho que mais o motor e o visual. A fala é muito demorada. [...] na parte dele ter limite, porque a gente trabalha esta parte de limite também, ele vai sair da sala quando é o horário, ele tem o horário do lanche, a rotina, porque eles têm que ter rotina". (P2)

"Ah, de um ano pro outro você vê, você chega no outro ano já vê que a criança desenvolveu bastante né. [...] de um ano pra outro a gente vê que eles mudam. Já reagiram um pouco mais. É legal ver eles se desenvolvendo melhor". (P3)

P1 e P2 (professoras) afirmam que a estimulação essencial é importante principalmente para a socialização, desenvolvimento motor e sensorial das crianças, 
como é possível verificar no quadro. P1 e P2 também consideram que a estimulação essencial é importante para as etapas posteriores da escolarização das crianças, principalmente pelo fato de que possibilita a aprendizagem de regras, limites e rotinas, $\mathrm{o}$ que de acordo com as entrevistadas facilitará a adaptação das crianças às próximas séries.

Já P3 e P4 (auxiliares) também consideram que a estimulação essencial é importante, mas têm mais dificuldade de apontar exemplos específicos de tal importância. Apenas afirmam que observam o desenvolvimento das crianças de um ano para o outro, mas não especificam em quais aspectos. É possível perceber, por meio das falas apresentadas, que as professoras apresentam mais clareza sobre a importância da estimulação essencial do que as auxiliares, muito embora as suas falas indiquem apenas aspectos específicos do desenvolvimento. Isto pode ocorrer pelo fato de as auxiliares apresentarem um tempo de experiência muito menor na área do que as professoras, levando-as e terem menos possibilidade de visualizar os resultados das intervenções realizadas junto às crianças.

O desenvolvimento da linguagem foi um aspecto pouco mencionado pelas participantes no que diz respeito à importância da estimulação essencial. Por outro lado, é interessante notar, que elas mencionam esse processo como uma espécie de ajuda ou preparação para etapas de escolarização posteriores. Ou seja, trata-se de uma concepção de escolarização que não considera a linguagem enquanto conteúdo estruturante, conforme é previsto em documentos oficiais de referência do ensino infantil (BRASIL, 2010).

Ao longo das entrevistas as mesmas o fizeram apenas diante de questionamentos específicos da pesquisadora. É importante lembrar que ao destacar a importância da linguagem no desenvolvimento infantil, Vigotsky (1997) enfatiza a noção de signo como instrumento mediador e constituidor das funções superiores: “[...] um signo é sempre, originalmente, um meio/modo de interação social, um meio para influenciar os outros e só depois se torna um meio para influenciar a si próprio.” (VYGOTSKY, 1997, p.83). Sendo assim, é importante que as profissionais que atuam em programas de estimulação essencial conheçam esse valor da linguagem para as crianças com as quais trabalham, bem como compreendam a importância de que tal habilidade seja favorecida, desde os primeiros anos de vida. 


\section{O planejamento das atividades na estimulação essencial e a implicação deste planejamento no processo de desenvolvimento linguístico}

De acordo com as professoras, há três tipos de planejamento na estimulação essencial: o anual, o bimestral e o semanal. Os dois primeiros são elaborados em conjunto, com a participação de todas as professoras da estimulação essencial. Ou seja, o planejamento anual e bimestral é igual para todas as turmas de estimulação essencial. O planejamento semanal, chamado de 'semanário' pelas participantes, é realizado individualmente por cada professora, normalmente em sua hora atividade ou em casa, quando não há tempo suficiente para fazê-lo na instituição. Os planejamentos contemplam os conteúdos a serem trabalhados, e as atividades que contemplarão tais conteúdos.

"Eu faço planejamento semanal, porque é muita repetição né. A gente trabalha muita repetição. Através desse meu programa aqui (professora mostra um planejamento), eu preparo o meu semanário. [...] eu tenho ele aqui no caderno. Eu faço uma semana. Eu só escrevo o que vou fazer. Esse aqui na verdade é de 2012, mas ele não teve muita mudança, porque mudaram as crianças". (P1)

"Não (não tenho um planejamento), vou seguindo o dela (da professora), que é proposto pela escola". (P4)

As falas de P1 e P2 exemplificam a forma como o planejamento é realizado. A fala de P1 revela um dado interessante: o reaproveitamento do planejamento de anos anteriores. É possível pensar em prejuízos e benefícios de tal prática. Por um lado, quando a professora reaproveita um planejamento já existente é possível aperfeiçoá-lo cada vez mais, aperfeiçoando gradativamente as atividades realizadas. Entretanto, correse o risco de utilizar intervenções generalizadas, que não foram pensadas especificamente para atender às necessidades das crianças da turma.

No caso específico da linguagem, é importante que as intervenções sejam personalizadas, já que cada criança possuirá condições comunicativas diferentes em uma turma de estimulação essencial, por conta da diversidade e particularidades de desenvolvimento. Além disso, as crianças também se encontrarão em patamares diferentes do desenvolvimento desta habilidade, seja pela variação de idade, já que as turmas de estimulação essencial são compostas por crianças entre 0 e 3 anos de idade, mas principalmente pelas diferentes condições sociais e culturais às quais as mesmas são expostas. Sendo assim, o aproveitamento do planejamento de anos anteriores pode 
ser prejudicial na medida em que as crianças que estão sendo atendidas no ano atual, podem não tirar proveito das intervenções que foram realizadas junto a crianças de anos anteriores, já que não foram pensadas a partir de suas necessidades e potencialidades específicas.

Mesmo assim, ou seja, mesmo considerando estes aspectos particulares, ainda precisamos mencionar a necessidade de se ter um planejamento voltado para o ensino infantil e não para aspectos clínicos ou aspectos específicos do desenvolvimento individual destas crianças.

\section{O lugar da linguagem no programa de estimulação essencial}

É possível perceber que a linguagem verbal aparece com muito mais frequência na fala das entrevistadas do que a linguagem não verbal. Apesar disto, o relato das mesmas revela que a maioria das crianças que estão no programa apresentam acentuadas dificuldades relacionadas à linguagem verbal: isto será evidenciado por meio das falas das participantes no quadro abaixo. Este é um ponto interessante a ser discutido, pois talvez o caminho para superar ou amenizar tais dificuldades seja justamente iniciar as intervenções pela linguagem não verbal, para que gradualmente, dentro das possibilidades de cada criança, ela vá se transpondo para a oralidade, nos casos em que seja vislumbrada tal possibilidade.

"Eu tenho um agora, que ele já transmite uma ideia mesmo sabe, de casa mesmo ele já conta alguma coisa que você entende, tipo assim: 'a mãe foi baiá na mulher' [...] Ele é um exceção. A maioria não consegue”. (P1)

"[...] tu trabalha com pedaços de lixa, dai eu tenho madeiras, pedacinhos de grama sintético, esponja, várias texturas de esponja. Então tu trabalha não só na mão como no rosto, o que auxilia na fala. [...] massagem, exercícios fonoarticulatórios de língua, bochecha, (professora faz alguns exercícios para demonstrar, estalando a língua e movimentando as bochechas). Essa parte do maxilar a gente faz massagem. Tu coloca a mãozinha dele na garganta e na da gente (professora emite alguns sons). Com apito, lingua de sogra para o sopro. Bolinha de sabão que ajuda para trabalhar a respiração”. (P2)

\section{a) A linguagem verbal}

O processo de aquisição e desenvolvimento da linguagem envolve questões complexas de naturezas individual e ambiental. Quando se fala deste processo em crianças com alterações sociocognitivas, neuromotoras ou sensorioperceptivas, essa 
complexidade é ainda maior, pois essa aquisição ocorre de maneira diferente (BISHOP, 2006).

P2 falou sobre a importância de expor a criança a desafios para o desenvolvimento da linguagem oral. Esta fala da participante demonstra os conceitos de área de desenvolvimento real x zona de desenvolvimento potencial discutidos por Vygotsky (1988). O autor afirma que a área de desenvolvimento real são aquelas habilidades ou tarefas que a criança já domina, realiza sem precisar da ajuda de outras pessoas. Já a zona de desenvolvimento potencial refere-se àquilo que a criança realiza com a ajuda de outras pessoas. Para Vygotsky (1988), o papel do professor é intervir justamente sobre a segunda, fazendo com que as habilidades potenciais tornem-se reais, e criando constantemente novas possibilidades para a zona de desenvolvimento potencial.

Uma das professoras (P2) também citou atividades que servem para fortalecer o aparato fonoarticulatório e que, na opinião dela, irão auxiliar no desenvolvimento da linguagem oral. Todas as atividades citadas pela participante irão contribuir para o desenvolvimento de aspectos físicos da criança, ou seja, o fortalecimento do aparato fonoarticulatório. Esta é uma intervenção importante, já que o desenvolvimento da linguagem verbal também depende de que tal aparato seja saudável e íntegro. Entretanto, de acordo com a teoria de Vygotsky (2001), o desenvolvimento do aparato fonoarticulatório é apenas o início do processo de desenvolvimento da linguagem em sua forma superior. Para ele, a linguagem assim como outras habilidades humanas não encontra sua essência nos aspectos biológicos do sujeito, mas sim no social. Sendo assim, é importante que as educadoras tenham clareza de que tais intervenções são importantes para o desenvolvimento da linguagem, mas não são suficientes sem os estímulos sociais e culturais adequados.

Além disso, observamos que a fala, novamente aparece como sinônimo de linguagem, e é importante ressaltar que ela é apenas um dos meios de expressão da linguagem. Sendo assim, a criança que não se comunica por meio da fala pode ser equivocadamente considerada como alguém que não desenvolveu linguagem. Tal ideia precisa ser revista, já que o próprio Vygotsky (2001) ressalta em sua obra que este sistema de signos também pode assumir outras configurações como o gestual e o visual.

Dentro desse mesmo contexto, também é importante enfatizar para estas profissionais, em orientações específicas, que há casos nos quais é mais difícil vislumbrar um desenvolvimento da oralidade. Nestes casos, é de extrema importância 
que sejam inseridos na rotina destas crianças, o quanto antes, sistemas alternativos, complementares e/ou suplementares de comunicação. Isso deve ser feito por um profissional especializado que auxilie e assessore o professor em sua rotina de sala de aula, pois essa forma de comunicação pode ser necessária em todos os contextos da criança (DELIBERATO, 2013; 2008).

\section{b) A linguagem não verbal}

A linguagem não verbal foi mencionada pelas participantes apenas diante de questionamentos diretos da pesquisadora a respeito do tema. Isto pode indicar que as participantes consideram que a linguagem verbal é o objetivo final a ser atingido, desconsiderando a importância que a linguagem não verbal tem neste processo. Além disso, ao apresentar esta concepção as participantes também parecem desconsiderar que em alguns casos essa pode não ser a modalidade da qual a criança se beneficiará. É importante salientar que, pela teoria sociointeracionista, o desenvolvimento da linguagem inicia-se justamente pela linguagem não verbal.

"Tu vai na minha sala, eu tenho três que gritam, mas gritam, é ótimo, eles estão gritando, eles estão se defendendo". (P1)

"Às vezes se alguém que comer eles fazem assim (aponta para a boca), com o dedo na boca, é assim que eles fazem. Através do olhar também né”. (P3)

De acordo com Vygotsky (2001), as primeiras manifestações de linguagem da criança são as pré-linguísticas, como o choro, o balbucio e o riso. Mesmo que estas tentativas de comunicação sejam ainda muito rudimentares, elas são fundamentais para o desenvolvimento psíquico da criança. Isto porque, conforme o adulto ou a criança mais experiente vai atribuindo significados a estas manifestações, a criança vai desenvolvendo e aprimorando cada vez mais seus recursos comunicativos. Sendo assim, tais manifestações não devem ser ignoradas, mas valorizadas e mediadas pelo professor para que, dentro das possibilidades de cada criança, vá se estabelecendo no repertório da mesma como linguagem oral. Além disso, nos casos em que a linguagem oral é comprometida e ainda não se estabeleceu outra forma de se comunicar, estes são os meios fundamentais de comunicação que a criança dispõe.

As formas mais citadas de linguagem não verbal foram os gestos, o choro e os gritos das crianças. Apesar de as participantes voltarem-se à linguagem não verbal 
apenas depois de um direcionamento específico da pesquisadora, todas reconheceram que é uma habilidade importante, pois permite a comunicação das crianças que apresentam dificuldades na oralidade. Entretanto, mesmo que as participantes atribuam importância para este tipo de linguagem, ela parece ser considerada uma habilidade secundária, de menor importância do que a linguagem verbal. Não podemos ignorar que estamos diante de casos muito distintos de desenvolvimento dessa habilidade e, portanto, não se pode admitir essa comparação de desenvolvimento típico com casos em que ele ocorre de maneira diferente e/ou atípica. A fala sempre parece ser o objetivo final a ser atingido. Observa-se também que novamente as participantes referem-se à linguagem apenas em sua função comunicativa, relativizando a importância que a mesma tem para a formação de conceitos e o desenvolvimento do pensamento abstrato das crianças.

Quando as participantes relatam o uso frequente da linguagem não verbal das crianças, também é possível remeter-se ao conceito de compensação (grifo nosso), utilizado por Vygotsky (1997) em seus estudos sobre defectologia. Para ele, toda deficiência gera no comportamento da criança mecanismos de compensação, que seria a busca intensa do organismo pelo desenvolvimento. Assim, como a maior parte das crianças (de acordo com o relato das participantes) apresentam dificuldades de oralidade, as mesmas podem estar intensificando o uso da linguagem não verbal como um mecanismo de compensação, especialmente em casos nos quais a linguagem verbal não chega a se desenvolver. Novamente, ressalta-se a importância de que este mecanismo seja reforçado e valorizado pelas educadoras, e não ignorado.

\section{A importância da ludicidade articulada à estimulação essencial e ao desenvolvimento da linguagem}

O brinquedo e a brincadeira foram citados em vários momentos como sendo importantes para o desenvolvimento geral das crianças atendidas na estimulação essencial e para o desenvolvimento da linguagem. As participantes citam o uso do brinquedo como um método eficaz para que a criança aprenda a nomear objetos e interaja mais facilmente com as pessoas à sua volta. O brinquedo também aparece como instrumento para a estimulação das habilidades motoras e sensório perceptivas das crianças.

"Porque tu trabalha tanto o lúdico, tanto a brincadeira, esta parte motora até de massinha de modelar, eles rasgam papel, eles 
gostam muito de rasgar o papel, tem crianças que chegam e não conseguem rasgar o papel, não conseguem amassar o papel”. (P2)

"Pra brincar também né, no brinquedo, pra escutar o que a gente tá falando. A gente pensa que eles não entendem, você vai notando com o passar dos dias. Você fica ali né, você fala, eles entendem, até o PC né”. (P3)

"[...] com os brinquedos eles sabem o nome e vão falando, a gente vai contando toda uma história do brinquedo, eles vão gravando alguma coisa". (P4)

É possível perceber por meio das falas apresentadas no quadro que uma das participantes (P2) relatou que muitas vezes os outros profissionais da instituição menosprezam a importância que a brincadeira tem para as crianças da estimulação essencial, não entendem a seriedade do trabalho que envolve o brinquedo e o brincar.

Uma função importante do brincar, que não apareceu no relato das participantes, é que o mesmo impulsiona o desenvolvimento da capacidade de abstração. Para Vygotsky (2008), na brincadeira a criança aprende a desvincular-se daqueles objetos que estão fisicamente ausentes e passa a ter sua ação direcionada pelo pensamento, e não apenas pelo objeto em si. Este processo possibilita o desenvolvimento crescente do pensamento abstrato, fazendo com que a criança aprenda a dar significado e sentido ao mundo à sua volta. É importante também pensar o quanto o pensamento abstrato está relacionado ao desenvolvimento da linguagem, pois esta é um conjunto de signos utilizados para representar o mundo. Assim, pode-se dizer que o desenvolvimento do pensamento abstrato impulsiona o desenvolvimento da linguagem, e vice-versa. Diante disto, percebe-se que a função do brinquedo e do brincar vai muito além da interação e da estimulação sensorial, que foram mencionadas pelas participantes.

Outros autores como Brougère (2002), Kishimoto e Ono (2008), e Carneiro (2010) também apontam para a importância do brincar para o desenvolvimento global da criança. Brougère (2002) afirma que o brincar constitui-se não apenas como um espaço de expressão da subjetividade e da cultura humana, mas principalmente apresenta-se como uma possibilidade de que a criança seja construtora ativa da cultura na qual está inserida. Kishimoto e Ono (2008) discutem a importância do brincar para a constituição da identidade do sujeito, inclusive da identidade de gênero. Carneiro (2010) afirma que, além do consenso generalizado de que o brincar é benéfico para o desenvolvimento físico, social, cognitivo e emocional da criança, é preciso considerar tal ação como forma de expressão simbólica da criança. Ou seja, novamente evidencia- 
se a importância de que o brincar não seja visto na estimulação essencial apenas como um instrumento de entretenimento, ou de estimulação sensorial. Ele possui várias outras funções, incluindo a emancipação da criança como sujeito social, já que possibilita que a mesma não apenas apreenda os elementos da cultura na qual está inserida, mas seja construtora ativa desta cultura.

\section{Dificuldades encontradas pelas professoras na estimulação essencial relacionadas aos aspectos de linguagem}

Apesar de o tema "dificuldades no trabalho" não ter sido diretamente abordado ao longo das entrevistas, as participantes relataram uma série de percalços que vivenciam nas turmas de estimulação essencial em seu trabalho diário.

"Tem alunos que a gente percebe que são estimulados em casa, bastante, e já tem alguns que não. [...] A maioria da minha turma é mais na escola". (P1)

"Porque não tem material, tem, mas é muito caro e é difícil, então a gente pesquisa e a gente faz muito material". (P2)

"[...] eu não tenho tempo, eu tenho hora atividade mas eu tava sem hora atividade, agora eu tenho na segunda feira os dois primeiros, na quarta feira um horário, que daí não dá tempo pra nada, e na quinta feira eu tenho os dois primeiros. E daí nesses horários eu tenho que organizar a chamada, aí eu tenho a agenda deles que vão todo dia com o relato das atividades, e daí o semanário. Então geralmente o semanário tu leva pra casa, tu faz em casa, tu não tem como fazer aqui. E quando é atividade assim, alguma coisa pra eles, também em casa". (P2)

Uma das dificuldades relatadas por duas participantes é a de trabalhar em grupo com as crianças. Segundo elas, isto acaba exigindo que o atendimento seja individualizado, o que se torna difícil por conta do número de crianças nas turmas. As professoras (P1 e P2) relataram que sentem falta de uma participação mais efetiva da família. Segundo elas, as atividades realizadas na escola não têm uma continuidade em casa, o que dificulta o desenvolvimento das crianças. Por outro lado, em nenhum momento foi mencionado sobre algum trabalho da escola para incentivar essa participação. Nesse sentido, alertamos para o fato de se tomar cuidado com o comportamento de culpabilizar a família pelas dificuldades encontradas no trabalho junto às crianças. No estudo de Oliveira et al. (2013) este comportamento foi identificado não só em relação à família, mas também em relação ao próprio indivíduo. 
Isto é, as dificuldades que a criança pode apresentar no processo de ensinoaprendizagem, em nenhum momento parecem ser assumidas pela escola.

Observamos, ainda, que todas as participantes afirmaram que encontram grande dificuldade em desenvolver a linguagem verbal das crianças. Segundo elas, isto acaba dificultando e em alguns casos até impossibilitando a comunicação das crianças entre si e com as professoras. Como discutido na categoria sobre "linguagem", de acordo com Vygotsky (2001) são os significados que os adultos atribuem às primeiras tentativas de comunicação da criança que irão contribuir para o desenvolvimento da linguagem. Sendo assim, as tentativas mais rudimentares de comunicação devem ser valorizadas e mediadas pelo educador para que se configurem em uso e função dessa habilidade.

Uma das professoras (P1) mencionou brevemente a incerteza que tem, em alguns momentos, sobre o diagnóstico de algumas crianças, atribuindo algumas dificuldades dela a isso, já que, segundo ela, sem conhecer as reais limitações da criança não é possível planejar e executar intervenções adequadas para cada caso. Vygotsky (1988) afirma que a função do professor é intervir sobre a zona de desenvolvimento potencial de criança, ou seja, aquilo que a criança realiza apenas com ajuda. Diante do relato da participante, pode-se pensar que esta dificuldade em conhecer as necessidades da criança provavelmente fará com que a professora também não consiga identificar quais são suas potencialidades; isto pode fazer com que as intervenções realizadas em sala de aula não sejam realmente voltadas à zona de desenvolvimento potencial, sendo um fator impeditivo para que a professora cumpra seu papel, de acordo com a concepção de Vygotsky (1988). No entanto, cumpre-nos alertar para o fato de nem sempre ser necessário o diagnóstico para o planejamento destas intervenções. A ferramenta maior e mais eficaz que temos para planejar qualquer intervenção, sem dúvida é a observação do dia a dia, independentemente do diagnóstico da criança (BRASIL, 2010).

Outra professora (P2) falou sobre a falta de material adequado para trabalhar com as crianças da estimulação essencial, sendo que o material existente normalmente apresente um alto custo, sendo inacessível para algumas instituições de ensino. Esta queixa acaba gerando impacto sobre outra situação, relatada pela mesma participante: a falta de tempo suficiente para realizar o planejamento das aulas. Percebe-se o quanto os dois problemas estão relacionados, pois além de as profissionais não terem à sua disposição tempo suficiente para realizar as funções inerentes à atuação em sala de aula, 
ainda precisam elaborar e confeccionar materiais didáticos para as intervenções com as crianças.

São escassos os estudos acerca de concepções de professores em programas de estimulação essencial. Especificamente falando sobre as dificuldades em relação ao processo de inclusão do ponto de vista de professores, Capellini e Rodrigues (2009) desenvolveram um estudo, também por meio de entrevistas. Dentre as principais dificuldades apontadas pelos professores, estavam as características dos alunos e do seu ambiente de origem, que não ofereciam possibilidade de desenvolvimento daquelas habilidades pré-acadêmicas valorizadas pela escola. Os professores se referiram às condições ruins da escola, como número excessivo de alunos por sala, falta de apoio técnico, dentre outros, e às dificuldades em relação à formação inicial e/ou continuada, alegando serem deficitárias.

\section{Considerações finais}

As entrevistas com as participantes evidenciaram aspectos que devem ser alvo de reflexão quando se discute a configuração de programas de estimulação essencial enquanto suporte para os processos de desenvolvimento, aprendizagem e formação humana, de modo geral.

Em primeiro lugar, foi possível perceber que as intervenções especificamente voltadas ao desenvolvimento da linguagem das crianças ainda são escassas, e quando ocorrem são de forma pontual e pouco planejadas. Isto pode dever-se ao fato de as profissionais entrevistadas não conhecerem as dimensões e implicações deste desenvolvimento em relação a todo o processo de desenvolvimento infantil e constituição do sujeito.

Além disso, trata-se de uma inconsistência entre o currículo do programa de estimulação essencial analisado e os pressupostos da etapa de ensino na qual as crianças fazem parte. Isso é, dentro de uma Escola de Educação Básica, na modalidade de Educação Especial, não foi possível vislumbrar a linguagem enquanto conteúdo estruturante da Educação Infantil. Isto significa que observamos poucos relatos que contemplavam a linguagem (oral ou escrita) em seus usos sociais ou enquanto função comunicativa.

Há que se repensar, neste sentido, não apenas a formação inicial de tais profissionais, mas também a continuada, uma vez que a escassez de informações pode 
empobrecer sua atuação junto às crianças, em momentos cruciais deste desenvolvimento. As lacunas nestas formações podem afetar, de maneira drástica, o planejamento das intervenções.

Outro dado evidenciado por meio das entrevistas é o de que as participantes demonstraram não priorizar o planejamento voltado às necessidades de cada criança, uma vez que reaproveitam planejamentos de anos anteriores. Tal postura pode ser prejudicial não apenas para as crianças atendidas, mas para todo o programa de estimulação essencial, já que com isto deixa-se de desenvolver novas intervenções ou até mesmo aperfeiçoar as já existentes.

Há também que se pensar nas dificuldades enfrentadas pelas profissionais, tanto as apontadas diretamente pelas participantes, quanto aquelas percebidas em seu discurso. Falta de envolvimento da família no processo, pobre articulação entre profissionais de educação e saúde, falta de materiais e condições de trabalho precárias, separação do cuidar e do educar são algumas delas. Por outro lado, não foi possível identificar na fala das participantes ações que favorecem a aproximação ou participação da família nesse processo.

Tais dificuldades poderiam ser solucionadas não apenas com investimento do Estado para a melhoria das condições materiais dos programas de estimulação essencial, mas principalmente com uma mudança das práticas adotadas neste contexto. De modo geral, faz-se necessária a superação crescente da ideia de que a pessoa com deficiência deve adaptar-se às condições oferecidas pelo meio, como se o sucesso ou fracasso de tais pessoas fosse um mérito essencialmente individual. É preciso então, rever o caráter clínico e individualizante que tais intervenções apresentam e pensar em um modelo de estimulação essencial que promova condições de suporte às crianças atendidas, envolvendo outros contextos além da escola especial, como a família, a escola comum, e a sociedade em geral. 
ABSTRACT: The present study aimed to identify the teachers' conceptions about the development of children participating in a program of essential language stimulation. The study included two teachers and two assistants who work at the School of Basic Education, Special Education (APAE), in an inland city of Paraná. Semi-open interviews using a semi-structured guide were performed. The recording of interviews was performed by a recorder. Then, they were transcribed and analyzed using thematic categorization. From the data collected, five categories of analysis. Vygotsky's theoretical framework and current studies on the subject were used as the basis of this discussion. The interviews showed that participants' concepts about language are closely related to speech development, diminishing the importance of other forms of language and even establishing confusion between orality and language. Moreover, the communicative function of language prevails in the reports prepared by the participants, and conceptions about the importance of this skill for the other psychological superior functions or as a structuring content for the children's schooling is virtually nonexistent.

KEY WORDS: Special education. Essential stimulation. Language.

\section{REFERENCIAS}

ARANHA, M. S. F. Paradigmas da relação da sociedade com as pessoas com deficiência. Revista do Ministério Público do Trabalho, Brasília, n.21, p.160-173, mar. 2001.

BISHOP, D. What causes specific language impairment in children? Current Directions in Psychological Science, [S.1.], v.15, n.5, p.217-221, 2006.

BRASIL. Ministério da Educação. Diretrizes curriculares nacionais para a educação infantil. Brasília: MEC/SEB, 2010.

1995.

Diretrizes educacionais sobre estimulação precoce. Brasília: MEC/SEB,

Política Nacional de educação especial na perspectiva da educação inclusiva. Brasília: MEC/SEESP, 2008.

BROUGÈRE, G. A criança e a cultura lúdica. In: KISHIMOTO, T. M. (Org.). O brincar e suas teorias. São Paulo: Pioneira Thomson Learning, 2002. p.19-32.

BRUST, J.; LOPES, M. I. Concepções de professores de uma escola de educação infantil sobre seu trabalho e a estimulação precoce como recurso em sala de aula. Revista Destaques Acadêmicos, Lajeado, n.3, p.1-10, 2010.

CAPELliNI, V. L.; RODRIGUES, O. M. R. Concepções de professores acerca dos fatores que dificultam o processo da educação inclusiva. Educação, Porto Alegre, v.32, n.3, p.355-364, 2009. Disponível em: <http://www.revistaseletronicas.pucrs.br>. Acesso em: 20 jan. 2014. 
CARDOSO, R. M. et al. Conhecimento de mães e auxiliares de desenvolvimento infantil referentes ao desenvolvimento da linguagem de crianças de 0 a 24 meses. Revista Brasileira de Crescimento e Desenvolvimento Humano, São Paulo, v.13, n.2, p.85-94, 2003.

CARNEIRO, M. A. B. Cócegas, cambalhotas e esconderijos: construindo cultura e criando vínculos. São Paulo: Articulação Universidade Escola, 2010.

DE NARDIN, A. C.; MENEZES, E. P. Representações docentes: o olhar para o aluno necessidades educacionais especiais. Revista Educação Especial, Santa Maria, v.21, p.63-74, 2008.

DELIBERATO, D. Comunicação alternativa: informações básicas para o professor. In: OLIVEIRA, A. S.; OMOTE, S.; GIROTO, C. M. (Org.). Inclusão escolar: as contribuições da Educação Especial. São Paulo: Cultura Acadêmica Editora, 2008. p.233-250.

Comunicação alternativa na escola: possibilidades para o ensino do aluno com deficiência. In: ZABOROSKI, A. P.; OLIVEIRA, J. P. (Org.). Atuação da fonoaudiologia na escola: reflexões e práticas. 1.ed. Rio de Janeiro: WAK Editora, 2013. p.71-90.

DESSEN, M. A.; COSTA JUNIOR, A. L. A ciência do desenvolvimento humano: tendências atuais e perspectivas futuras. Porto Alegre: ARTMED, 2005.

HEKAVEI, T.; OLIVEIRA, J. P. Evoluções motoras e linguísticas de bebês com atraso de desenvolvimento na perspectiva de mães. Revista Brasileira de Educação Especial, Marília, v.15, n.1, p.31-44, jan./abr. 2009. Disponível em: <http://www.scielo.br/scielo.php?pid=S1413-65382009000100004\&script=sci_arttext $>$. Acesso em: 12 fev. 2014.

KISHIMOTO, T. M.; ONO, A. T. Brinquedo, gênero e educação na brinquedoteca. Pro-posições, Campinas, v.19, n.3, p.209-223, set./dez. 2008.

MAJNEMER, A.; ROSENBLATT, B. Reability of parental recall of development milestones. Pediatric Neurology, [S.1.], v.10, n.4, p.304-308, 1994.

NUNES, C. C.; AIELLO, A. L. R. Interação entre irmãos: deficiência mental, idade e apoio social da família. Psicologia: Reflexão e crítica, Porto Alegre, v.21, n.1, p.42-50, 2008 .

OLIVEIRA, J. P. et al.Concepções de professores sobre a temática das chamadas dificuldades de aprendizagem. Revista Brasileira de Educação Especial, Marília, v.18, n.1, p.93-112, 2012.

OLIVEIRA, M. K.Vygotsky e o processo de formação de conceitos. In: LA TAILLE, Y.; OllVEIRA, M. K.; DANTAS, H. Piaget, Vygotsky, Wallon: teorias psicogenéticas em discussão. São Paulo: Summus, 1992. p.23-34.

PEREIRA-SILVA, N. L.; DESSEN, M. A. Crianças com e sem síndrome de Down: valores e crenças de pais e professores. Revista Brasileira de Educação Especial, Marília, v.13, n.3, p.429-446, 2007. 
QUATRIN, L. B.; PIVETTA, H. M. F. Inclusão escolar e concepções docentes: do desejo idealizado à realidade prática. Revista Educação Especial, Santa Maria, n.31, p.49-61, 2008.

VYGOTSKY, L. S. A brincadeira e o seu papel no desenvolvimento psíquico da criança. Revista Virtual de Gestão de Iniciativas Sociais, Rio de Janeiro, p.23-36, jun. 2008. Disponível em: <http://xa.yimg.com/kq/groups/32960205/729519164/ ame/artigo+ZOIA+PRESTES.cg--.pdf>. Acesso em: 12 jun. 2010.

. Aprendizagem e desenvolvimento intelectual na idade escolar. In: VYGOTSKY, L.S.; LURIA, A. R.; LEONTIEV, A. N. Linguagem, desenvolvimento e aprendizagem. São Paulo: Ícone: Editora da Universidade de São Paulo, 1988. p.103117.

Obras completas. Tomo V. Tradução de M. C. Ponce Fernández. Ciudad de La Habana, Cuba: Editorial Pueblo y Educación, 1997.

Pensamiento y lenguaje. Tomo II. Madrid: Editorial Pedagógica, 2001.

WARREN, J. R. et al. Characteristics as mediators in SES-health relationships. Social Science \& Medicine, [S.1.], n.59, p.1367-1378, 2004. 